\title{
Cross-talk between inflammation, coagulation/fibrinolysis and vascular access in hemodialysis patients
}

\author{
E. COSTA ${ }^{1,2,3}$, S. ROCHA ${ }^{2,3}$, P. ROCHA-PEREIRA $A^{3,4}$, E. CASTRO ${ }^{2,3}$, F. REIS ${ }^{5}$, F. TEIXEIRA ${ }^{5}$, V. MIRANDA $A^{6}$, M. DO \\ SAMEIRO FARIA ${ }^{6}$, A. LOUREIRO ${ }^{7}$, A. QUINTANILHA ${ }^{2,8}$, L. BELO ${ }^{2,3}$, A. SANTOS-SILVA ${ }^{2,3}$ \\ ${ }^{1}$ Instituto de Ciências da Saúde da Universidade Católica Portuguesa, Porto - Portugal \\ ${ }^{2}$ Faculdade Farmácia, Serviço de Bioquímica, Universidade do Porto - Portugal \\ ${ }^{3}$ Instituto Biologia Molecular e Celular (IBMC), Universidade do Porto - Portugal \\ ${ }^{4}$ Centro Investigação Ciências Saúde, Universidade Beira Interior, Covilhã - Portugal \\ ${ }^{5}$ Instituto de Farmacologia e Terapêutica Experimental, Faculdade Medicina, Universidade Coimbra - Portugal \\ ${ }^{6}$ FMC, Dinefro - Diálises e Nefrologia, SA - Portugal \\ ${ }^{7}$ Uninefro - Sociedade Prestadora de cuidados Médicos e de Diálise, SA - Portugal \\ ${ }^{8}$ Instituto Ciências Biomédicas Abel Salazar (ICBAS), Universidade do Porto - Portugal
}

\begin{abstract}
This work aimed to study the association between fibrinolytic/endothelial cell function and inflammatory markers in chronic kidney disease (CKD) patients undergoing hemodialysis (HD) and recombinant human erythropoietin (rhEPO) therapies, and its relationship with the type of vascular access (VA) used for the HD procedure. As fibrinolytic/endothelial cell function markers we evaluated plasminogen activator inhibitor type-1 (PAI1), tissue plasminogen activator (tPA) and D-dimers, and as inflammatory markers; C-reactive protein (CRP), soluble interleukin (IL)-2 receptor (s-IL2R), IL-6 and serum albumin levels. The study was performed in 50 CKD patients undergoing regular $\mathrm{HD}, 11$ with a central venous dialysis catheter (CVC) and 39 with an arteriovenous fistula (AVF), and in 25 healthy controls. Compared to controls, CKD patients presented with significantly higher levels of CRP, s-IL2R, IL-6 and D-dimers, and significantly lower levels of PAI-1. The tPA/PAI-1 ratio was significantly higher in CKD patients. We also found statistical significant correlations in CKD patients between D-dimers levels and inflammatory markers: CRP, albumin, s-IL2R and IL-6. When comparing the two groups of CKD patients, we found that those with a CVG presented statistically significant lower levels of hemoglobin concentration and albumin, and higher levels of CRP, IL-6, D-dimers and tPA. Our results showed an association between fibrinolytic/endothelial cell function and increased inflammatory markers in CKD patients. The increased levels of Ddimer, tPA and inflammatory markers in CKD patients using a CVC, led us to propose a relationship between the type of VA chosen for HD, and the risk of thrombogenesis. (J Vasc Access 2008; 9: 248-53)
\end{abstract}

Key words: Fibrinolytic activity, Chronic renal failure, Vascular access, D-dimers

\section{INTRODUCTION}

A successful hemodialysis (HD) procedure requires a functional vascular access (VA). Unfortunately, no major advances in the field of HD VA have been observed for the past $30 \mathrm{yrs}$, and this has probably contributed to VA dysfunction as being one of the most important causes of morbidity in the HD population (1). Access-related problems are responsible for $50 \%$ of the hospitalizations of HD patients (2). Currently, there are three main forms of HD VA: arteriovenous fistula (AVF), polytetrafluoroethylene
(PTFE) graft, and central venous catheter (CVC). Each of these forms has its own specific problems. AVF is the first choice for VA in patients undergoing chronic HD due to its relative low risk of infection and thrombosis. However, this type of VA has two major complications: initial failure to mature (primary non-function) and a later venous stenosis followed by thrombosis (3). A PTFE graft is relatively easy to place and ready to use; however, extremely high rates of stenosis, thrombosis, and infection are reported for this VA (4). CVC is the least desirable method of $\mathrm{HD}$ access. In a sense, every CVC placement repre- 
sents a failure: failure to prepare a native AVF in advance of initiating dialysis; failure to detect failing AV access and maintain its function, or create a suitable alternative. Nevertheless, catheters are an unavoidable necessity for many patients who do not have functional AV access for any reason. In recent years, the use of CVCs has increased in both acute and chronic uremic patients, and this could underlie the increased morbidity and mortality observed in these patients. The type of insertion and the management of a CVC can lead to several complications, namely infections and thrombosis (5).

An inflammatory stimulus triggers the synthesis of acute phase proteins, namely C-reactive protein (CRP), a prominent marker of inflammatory response in the general population and in chronic kidney disease (CKD) patients (6-8). CRP increases significantly in hemodialyzed patients, as compared with healthy controls $(8,9)$ and this rise appears to be a common feature in hemodialyzed patients. Chronic inflammation is also associated with atherosclerotic cardiovascular disease (CVD). CRP has been proposed as a new risk marker for CVD events; the high rate of morbidity and mortality observed in aemodialyzed patients $(10,11)$ could reflect the overlapping of these proinflammatory conditions and/or the inflammatory process in CKD patients favoring CVD events.

CKD patients undergoing HD have been also associated with complex hemostatic disorders, clinically expressed with both bleeding tendency and hypercoagulability, though its etiology is poorly understood. A disturbance in fibrinolysis was reported in CKD patients; however, studies of different fibrinolysis parameters in regularly dialyzed patients have yielded conflicting results, with some indicating suppressed fibrinolysis and others showing increased fibrinolysis (12). Several hemostatic proteins are also considered endothelial cell function markers, namely plasminogen activator inhibitor 1 (PAI-1) and tissue plasminogen activator (tPA), being both secreted by endothelial cells.

There are a considerable number of studies regarding the association of the type of VA with inflammatory markers and fibrinolytic/endothelial cell dysfunction $(13,14)$. However, only a few have investigated simultaneously inflammatory and fibrinolytic/endothelial cell dysfunction markers.

This work aimed to study the association between fibrinolytic/endothelial cell function and inflammatory markers in CKD patients undergoing HD and recombinant human erythropoietin (rhEPO) therapies, and its relationship with the type of VA used for the HD procedure.

\section{MATERIALS AND METHODS}

\section{Subjects}

We studied 50 CKD patients undergoing regular HD (32 males, 18 females; mean age $64.5 \pm 15.4$ yrs) and rhEPO therapy. These patients were recruited, after giving informed consent, from two HD clinics during a 1-year period. In 11 patients, the VA used for HD was a tunneled CVC, and in 39 patients it was an AVF. The CVC were used for a median period of 36 months (12-84 months). The incidence of VA infection in the unit is $5.6 \%$.

CKD patients were undergoing therapeutic HD three times per week, for 3-5 hr, for a median period of 36 months. All patients used the high-flux polysulfone FX-class dialyzers of Fresenius, 25 with FX60, 23 with FX80 and 2 with the FX100 dialyzer type.

Patients with autoimmune disease, malignancy, hematological disorders, and acute or chronic infection were excluded. We also excluded patients that presented, at the time of analysis with a positive blood culture result.

The control group included 25 healthy volunteers ( 8 males, 17 females; mean age $47.81 \pm 14.69$ yrs) presenting normal hematological and biochemical values, with no history of renal or inflammatory diseases, and, as far as possible, age and gender matched with CKD patients.

\section{Assays}

Blood samples were drawn from fasting controls and in the case of the hemodialyzed patients before the second dialysis session of the week. Blood samples were collected with and without anticoagulant [ethylenediamine tetraacetic acid (EDTA)], in order to obtain whole blood, plasma and serum.

Hemoglobin $(\mathrm{Hb})$ concentration and white blood cell (WBC) count were measured using an automatic counter (Sysmex K1000, Hamburg, Germany); differential leukocyte counts were evaluated in Wright-stained blood films. Serum CRP was measured by immunoturbidimetry (CRP latex HS Roche kit, Roche Diagnostics) and an enzyme-linked immunoabsorbent assay was used for measurement of serum soluble interleukin 2 receptor (s-IL2R) (human IL-2 SRa, R\&D systems, MN, USA). Serum albumin levels were measured using a colorimetric assay end-point method (Albumin Plus; Roche GmbH, Mannheim, Germany). Serum IL-6 levels were quantified using the $\mathrm{BD}^{\mathrm{TM}}$ Cytometric Bead Array Human Th1/Th2 Cytokine Kit II (BD Biosciences, USA, San Diego), and analyzed using the $\mathrm{BD}^{\mathrm{TM}} \mathrm{CBA}$ software. Plasma levels of PAI-1, tPA and D-dimers were 
evaluated by enzyme-linked immunoabsorbent assays (TintElize PAI-1, TintElize tPA and TintElize Ddimer, Biopool-Trinity Biotech Company, respectively). Serum iron concentration was determined using a colorimetric method (Iron, Randox Laboratories Ltd, Northern Ireland, UK), whereas serum ferritin and serum transferrin were measured by immunoturbidimetry (Ferritin, Laboratories Ltd, Northern Ireland, UK; Transferrin, Laboratories Ltd, Northern Ireland, UK). Transferrin saturation (TS) was calculated by the formula: TS $(\%)=70.9 \mathrm{x}$ serum iron concentration in $(\mu \mathrm{g} / \mathrm{dL}) /$ serum transferrin concentration in $(\mathrm{mg} / \mathrm{dL})$.

\section{Data analysis}

For statistical analysis, we used the Statistical Package for Social Sciences, version 14.0. Kolmogorov Smirnov statistics were used to evaluate sample normality distribution. Comparisons between groups were performed using the Kruskal-Wallis test and the Mann-Whitney U test (data with a non-Gaussian distribution) or one-way ANOVA supplemented with Tukey's HSD post-hoc test (data with a Gaussian distribution). Spearman's rank correlation coefficient was used to evaluate relationships between sets of data. Adjustment of statistical differences for confounding factors (comorbidity, age, sex and body mass index) was performed by analysis of covariance, after log transformation of variavel (when nec- essary). Multiple regression analysis using the stepwise method was used to determine independent factors affecting D-dimers levels. Significance was accepted at $\mathrm{p}<0.05$.

\section{RESULTS}

Tables I and II show rhEPO doses, hematological data, fibrinolytic and inflammatory cell markers, dialysis adequacy parameters, and nutritional and iron status, for controls and CKD patients.

Compared to controls, CKD patients presented with significantly higher counts of WBC and neutrophils, and higher levels of ferritin, CRP, s-IL2R, IL-6 and Ddimers. CKD patients also presented with significantly lower levels of $\mathrm{Hb}$ and PAI-1. The tPA/PAI-1 ratio was significantly higher for $\mathrm{CKD}$ patients.

When comparing the two groups of CKD patients, we found that those with a CVC VA presented with statistically significant lower levels of $\mathrm{Hb}, \mathrm{TS}$ and albumin, and higher levels of neutrophils, CRP, IL-6, Ddimers and tPA. Statistical significance remained after adjustment for the confounding factors. A trend to higher rhEPO doses to achieve target $\mathrm{Hb}$ levels (11-12 g/dL) was found in CKD patients using a CVC as VA (Tab. I).

We also found in CKD patients, statistically significant correlations between D-dimer levels and inflammatory markers: CRP, albumin, s-IL2R and IL-6 (Fig. 1).

TABLE I - HEMATOLOGICAL DATA, FIBRINOLYTIC AND INFLAMMATORY CELL MARKERS, DIALYSIS ADEQUACY PARAMETERS, AND NUTRITIONAL AND IRON STATUS IN CONTROLS AND CKD PATIENTS

\begin{tabular}{lcc}
\hline & $\begin{array}{c}\text { Healthy Controls } \\
(\mathbf{n = 2 5})\end{array}$ & $\begin{array}{c}\text { All CKD Patients } \\
(\mathbf{n}=\mathbf{5 0})\end{array}$ \\
\hline Weekly rhEPO $(\mathrm{IU} / \mathrm{Kg})$ dose & - & $271.29(79.22-577.29)$ \\
Hb $(\mathrm{g} / \mathrm{dL})$ & $14.12 \pm 1.27$ & $11.06 \pm 1.77 \mathrm{a})$ \\
WBC $(\mathrm{x} \mathrm{10} / \mathrm{L})$ & $5.80 \pm 1.60$ & $10.03 \pm 4.54 \mathrm{a})$ \\
Neutrophils $\left(\mathrm{x} 10^{9} / \mathrm{L}\right)$ & $3.00 \pm 1.00$ & $6.08 \pm 3.01 \mathrm{a})$ \\
Platelets $(\mathrm{x} \mathrm{10} / \mathrm{L})$ & $242.12 \pm 78.57$ & $212.48 \pm 98.39$ \\
CRP $(\mathrm{mg} / \mathrm{dL})$ & $1.75(0.76-4.70)$ & $5.75(1.90-14.00) \mathrm{a})$ \\
s-IL2R $(\mathrm{nmol} / \mathrm{L})$ & $758.83 \pm 234.95$ & $4199.94 \pm 1762.82 \mathrm{a})$ \\
IL-6 $(\mathrm{pg} / \mathrm{mL})$ & $1.90(0-3.75)$ & $7.8(3.85-15.05) \mathrm{a})$ \\
Albumin $(\mathrm{g} / \mathrm{dl})$ & - & $3.84 \pm 0.42$ \\
D-dimer $(\mathrm{ng} / \mathrm{mL})$ & $63.50(51.94-77.41)$ & $157.26(97.72-417.09) \mathrm{a})$ \\
tPA $(\mathrm{ng} / \mathrm{mL})$ & $4.72 \pm 2.95$ & $4.60 \pm 3.57$ \\
PAI-1 $(\mathrm{ng} / \mathrm{mL})$ & $58.17 \pm 24.25$ & $42.85 \pm 23.53 \mathrm{a})$ \\
tPA/PAI-1 ratio & $0.09 \pm 0.06$ & $0.14 \pm 0.11 \mathrm{a})$ \\
Transferrin saturation $(\%)$ & $21.83 \pm 7.97$ & $22.89 \pm 11.06$ \\
Ferritin $(\mathrm{ng} / \mathrm{mL})$ & - & $389.65(186.58-604.90) \mathrm{a})$ \\
Ktv & - & $1.59 \pm 0.29$ \\
Urea reduction $(\%)$ & - & $26.98 \pm 8.53$ \\
Protein catabolic rate $(\mathrm{g} / \mathrm{Kg} /$ day $)$ & $(37.88-123.95)$ & $0.85 \pm 0.04$ \\
\hline
\end{tabular}

*Results are presented as mean \pm one standard deviation or as median values (inter-quartile range). a) $p<0.05$, vs. controls 
Fig. 1 - Correlation between D-dimer levels and inflammatory markers in CKD patients: CRP (A), albumin $(B), s-I L 2 R(C)$ and IL-6 (D). Circles represent patients with an AVF and triangle patients with a CVC.
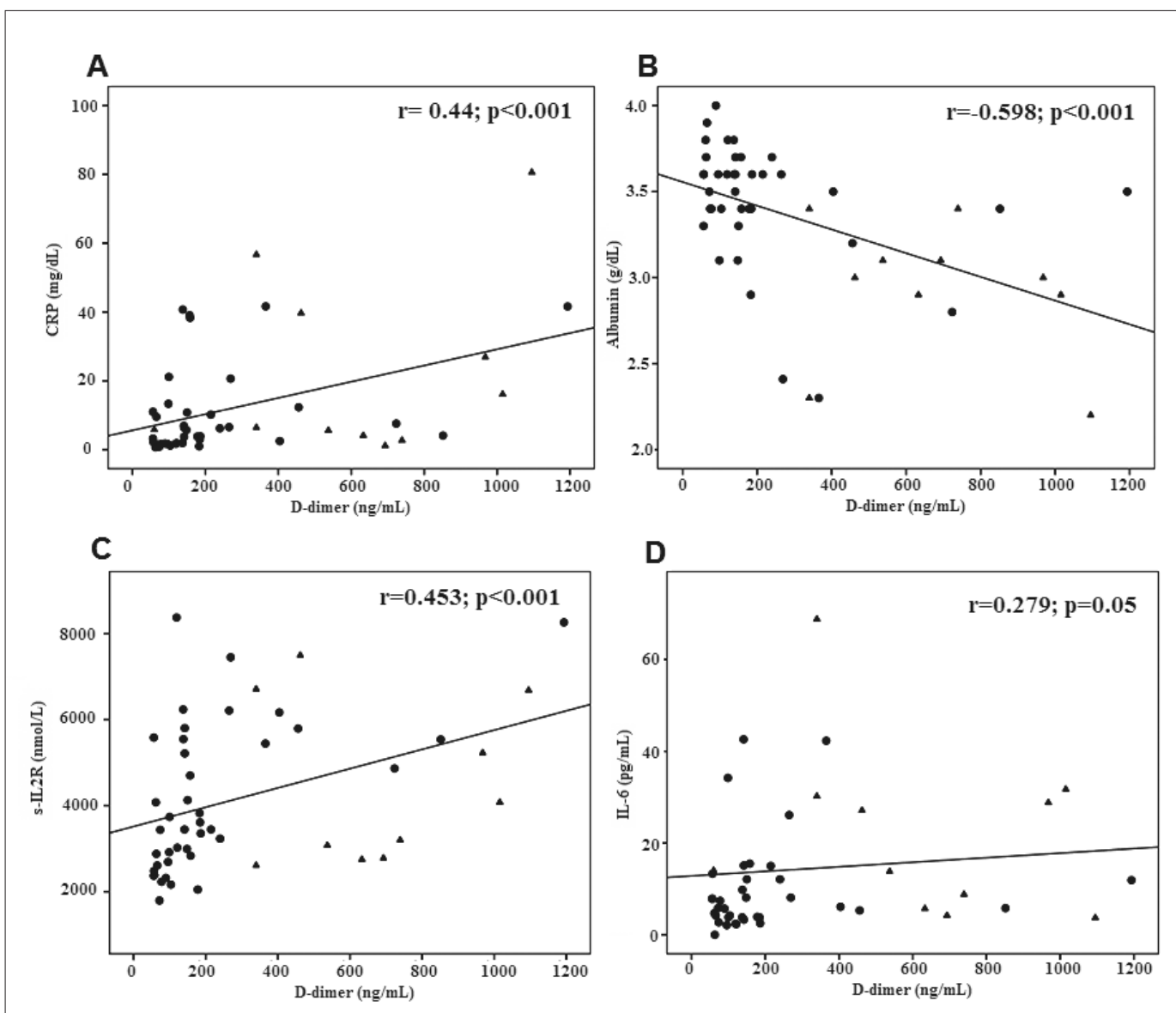

TABLE II - HEMATOLOGICAL DATA, FIBRINOLYTIC AND INFLAMMATORY CELL MARKERS, DIALYSIS ADEQUACY PARAMETERS, AND NUTRITIONAL AND IRON STATUS ACCORDING TO THE TYPE OF VASCULAR ACCESS

\begin{tabular}{|c|c|c|}
\hline & $\begin{array}{c}\text { CKD patients with AVF } \\
\qquad(n=39)\end{array}$ & $\begin{array}{l}\text { CKD patients with CVC } \\
\qquad(\mathrm{n}=11)\end{array}$ \\
\hline Weekly rhEPO (IU/Kg) dose & $156.01(56.82-582.52)$ & $456.12(102.56-575.54)$ \\
\hline $\mathrm{Hb}(\mathrm{g} / \mathrm{dL})$ & $11.27 \pm 1.86$ & $10.30 \pm 1.18 \mathrm{a})$ \\
\hline WBC $\left(\right.$ × $\left.10^{9} / \mathrm{L}\right)$ & $10.11 \pm 4.57$ & $9.77 \pm 4.64$ \\
\hline Neutrophils $\left(\right.$ x $\left.10^{9} / \mathrm{L}\right)$ & $5.90 \pm 2.96$ & $6.71 \pm 3.27$ a) \\
\hline Platelets $\left(\times 10^{9} / \mathrm{L}\right)$ & $203.17 \pm 85.19$ & $245.45 \pm 135.36$ \\
\hline $\mathrm{CRP}(\mathrm{mg} / \mathrm{dL})$ & $4.10(1.80-11.02)$ & $6.46(4.10-39.70) \mathrm{a})$ \\
\hline s-IL2R (nmol/L) & $4177.78 \pm 1745.00$ & $4278.51 \pm 1909.72$ \\
\hline IL-6 $(\mathrm{pg} / \mathrm{mL})$ & $5.95(3.80-12.40)$ & $14.00(5.70-30.20) \mathrm{a})$ \\
\hline Albumin (g/dl) & $3.94 \pm 0.36$ & $3.51 \pm 0.46 \mathrm{a})$ \\
\hline D-dimer $(\mathrm{ng} / \mathrm{mL})$ & $141.63(89.13-214.75)$ & $632.88(339.75-967.88)$ a) \\
\hline $\mathrm{tPA}(\mathrm{ng} / \mathrm{mL})$ & $3.94 \pm 2.21$ & $6.99 \pm 5.99$ a) \\
\hline PAI-1 (ng/mL) & $40.74 \pm 22.37$ & $50.37 \pm 27.06$ \\
\hline tPA/PAI-1 ratio & $0.14 \pm 0.12$ & $0.15 \pm 0.08$ \\
\hline Transferrin saturation (\%) & $25.19 \pm 10.84$ & $14.70 \pm 7.63 \mathrm{a})$ \\
\hline Ferritin $(\mathrm{ng} / \mathrm{mL})$ & $454.66(246.00-634.00)$ & $374.00(120.00-452.00)$ \\
\hline Ktv & $1.63 \pm 0.27$ & $1.50 \pm 0.36$ \\
\hline Urea reduction $(\%)$ & $25.78 \pm 7.01$ & $31.12 \pm 11.97$ \\
\hline Protein catabolic rate $(\mathrm{g} / \mathrm{Kg} /$ day $)$ & $0.87 \pm 0.04$ & $0.81 \pm 0.03$ \\
\hline
\end{tabular}

$*$ Results are presented as mean \pm one standard deviation or as median values (inter-quartile range). a) $p<0.05$ vs. CKD patients with an AVF 
Multiple regression analysis identified the weight $(\beta=-0.367 ; p=0.03)$, neutrophil count $(\beta=0.399$; $\mathrm{p}=0.001)$ and $\mathrm{s}-\mathrm{IL} 2 \mathrm{R}(\beta=0.279 ; \mathrm{p}=0.022)$ as the independent variables significantly associated with $\mathrm{D}$ dimers $\left(R^{2}=0.427\right)$.

\section{DISCUSSION}

CKD patients showed anemia, which, as reported in the literature (15), is mainly determined by the rate of renal insufficiency; and therefore, by the reduction in the renal secretion of erythropoietin. Additionally, CKD patients undergoing HD treatment presented with leukocytosis, neutrophilia and increased levels of IL-6, s-IL2R and CRP inflammatory molecules in the serum, confirming the presence of an inflammatory process.

In our CKD patients, we found low levels of PAI-1 and normal tPA plasma levels, suggesting that endothelial and fibrinolytic functions are not apparently altered in these patients (16). However, the tPA/PAI1 ratio was increased in our CKD patients, and the increase in this ratio has been described as a novel risk marker for recurrent myocardial infarction (17). We also found an increase in D-dimers in our patients; however, it is uncertain if the higher fibrin fragment $\mathrm{D}$-dimer value in CKD patients is a result of a higher activation of coagulation or of fibrinolysis. The higher tPA/PAI-1 ratio in CKD patients undergoing HD could suggest a higher fibrinolysis in these patients because only PAI- 1 presented a significantly lower value. However, we did not measure fibrinolytic activity. On the other hand, an interesting cross-talk has been proposed to exist between inflammation and coagulation (18). The higher inflammatory status observed in CKD patients could actually underlie coagulation activation. For instance, CRP is known to promote tissue factor synthesis (19), a potent procoagulant, by monocytes. The correlations and the multiple regression analysis that we found between D-dimer levels and inflammatory markers, underlie this hypothesis. From that perspective, the higher D-dimer levels in the CKD patients can also be observed as a marker of the inflammatory process in these patients.

When comparing our results to that previously described, we found some conflicting results, namely for PAI-1 that was been described to be increased $(20,21)$ or normal (22). For tPA, we found descriptions of normal values, as we found in this work, and other describing higher levels (20). These differences could be due to the difference between the studied CKD patient population and due to the type of kit used in the laboratorial evaluation. Increase D- dimer and tPA/PAI-1 ratio is the most consistent finding in most of the studies.

When we analyzed the results of the studied parameters according to the type of VA used, the CVC patients showed lower albumin and $\mathrm{Hb}$ values, and higher tPA, D-dimers, CRP and IL-6 levels as compared to those with an AVF, suggesting that these patients have an even higher inflammatory process. Our results also showed in CKD patients using a CVC as VA that they seem to require a higher rhEPO dose to achieve the target $\mathrm{Hb}$ levels, suggesting also cross-talk of erythropoiesis with inflammation.

It is important to note that we measured tPA antigen, which reflects both active free tPA and inert tPA bound to inhibitor(s) (23). Therefore, higher tPA values are not synonymous with higher activated fibrinolysis; higher t-PA values could result from endothelial dysfunction (23). Although tPA was higher in CVC patients, the tPA/PAI-1 ratio remained unchanged suggesting a similar activation of coagulation and fibrinolysis. The higher $\mathrm{D}$-dimer values are more likely to result from enhanced coagulation probably linked to a higher inflammatory stimulus, than to a higher fibrinolysis, as only a trend to higher PAI-1 levels was observed in CVC patients.

In summary, our results showed a relationship between hemostasis and increased inflammatory markers in CKD patients. The increased levels of D-dimer, tPA and inflammatory markers in CKD patients using a CVC, led us to propose a relationship between the type of VA chosen for HD, and the risk of thrombogenesis. It seems reasonable to assume that these patients could present with an increased risk for CVD events.

\section{ACKNOWLEDGEMENTS}

We are very grateful to FMC, Dinefro - Diálises e Nefrologia, SA and Uninefro - Sociedade Prestadora de Cuidados Médicos e de Diálise, SA, and to their nurses for the technical support.

This study was supported by a PhD grant (SFRH/BD/ 27688/2006) attributed to E. Costa by FCT.

Conflict of interest statement: none declared.

Address for correspondence:

Elísio Costa

Serviço de Bioquímica

Faculdade de Farmácia da Universidade do Porto

Rua Aníbal Cunha, 164

4099-030 Porto

Portugal

elisio_costa@hotmail.com 


\section{REFERENCES}

1. Santoro A. Confounding factors in the assessment of delivered hemodialysis dose. Kidney Int 2000; 77 (suppl): S19-27.

2. Ifudu O, Mayers JD, Cohen LS, et al. Correlates of vascular access and nonvascular access-related hospitalizations in hemodialysis patients. Am J Nephrol 1996; 16: 118-23.

3. Schwab SJ, Harrington JT, Singh A, et al. Vascular access for hemodialysis. Kidney Int 1999; 55: 2078-90.

4. Miller PE, Carlton D, Deierhoi MH, Redden DT, Allon M. Natural history of arteriovenous grafts in hemodialysis patients. Am J Kidney Dis 2000; 36: 68-74.

5. Mandolfo S, Piazza W, Galli F. Central venous catheter and the hemodialysis patient: a difficult symbiosis. J Vasc Access 2002; 3: 64-73.

6. Schindler R, Senf R, Frei U. Influencing the inflammatory response of haemodialysis patients by cytokine elimination using large-pore membranes. Nephrol Dial Transplant 2002; 17: 17-9.

7. Caglar K, Peng Y, Pupim LB, et al. Inflammatory signals associated with hemodialysis. Kidney Int 2002; 62: 1408-16.

8. Fishbane S. Hyporesponsiveness to recombinant human erythropoietin in dialysis patients. Nephrol Dial Transplant 2000; 29: 545-8.

9. Costa E, Lima M, Alves JM, et al. Inflammation, T-cell phenotype and inflammatory cytokines in chronic kidney disease patients under hemodialysis and its relationship to resistance to recombinant human erythropoietin therapy. J Clin Immunol 2008; 28: 268-75.

10. Hung C, Chen Y, Chou C, Yang C. Nutritional and inflammatory markers in the prediction of mortality in Chinese hemodialysis patients. Nephron Clin Pract 2005; 100: c20-6.

11. Wanner C, Zimmermann J, Schwedler S, Metzger T. Inflammation and cardiovascular risk in dialysis patients. Kidney Int 2002; 61 (suppl): S99-102.

12. Agras PI, Baskin E, Cengiz N, Kirazli S, Saatci U, Ozbek N. Global fibrinolytic capacity in children on dialysis. Thromb Res 2005; 115: 185-9.

13. Yu A, Egberg N, Jacobson SH. Haemostatic complications in haemodialysis patients: effect of type of vascular access and dialysis filter. Scand J Clin Lab Invest 2003; 63: 127-34.

14. Kanno Y, Kobayashi K, Takane H, et al. Elevation of plasma D-dimer is closely associated with venous thrombosis produced by double-lumen catheter in pre-dialysis patients. Nephrol Dial Transplant 2007; 22: 1224-7.

15. Iseki K, Kohagura K. Anemia as a risk factor for chronic kidney disease. Kidney Int Suppl 2007; 107: S4-9.

16. Shireman PK, McCarthy WJ, Pearce WH, Shively VP, Cipollone M, Kwaan HC. Elevations of tissue-type plasminogen activator and differential expression of urokinase-type plasminogen activator in diseased aorta. J Vasc Surg 1997; 25: 157-64.

17. Wiman B, Andersson T, Hallqvist J, Reuterwall C, Ahlbom A, deFaire U. Plasma levels of tissue plasminogen activator/plasminogen activator inhibitor1 complex and von Willebrand factor are significant risk markers for recurrent myocardial infarction in the Stockholm Heart Epidemiology Program (SHEEP) study. Arterioscler Thromb Vasc Biol 2000; 20: 2019-23.

18. Schoenmakers S, Reitsma P, Spek C. Blood coagulation factors as inflammatory mediators. Blood Cells Mol Dis 2005; 34: 30-7.

19. Carter AM. Inflammation, thrombosis and acute coronary syndromes. Diab Vasc Dis Res 2005; 2: 113-21.

20. Segarra A, Chacón P, Martinez-Eyarre C, et al. Circulating levels of plasminogen activator, and thrombomodulin in hemodialysis patients: biochemical correlations and role as independent predictors of coronary artery stenosis. J Am Soc Nephrol 2001; 12 : 1255-63.

21. Molino D, De Santo NG, Marotta R, Anastasio P, Mosavat M, De Lucia D. Plasma levels of plasminogen activator inhibitor type 1 , factor VIII, prothrombin activation fragment $1+2$, anticardiolipin, and antiprothrombin antibodies are risk factors for thrombosis in hemodialysis patients. Semin Nephrol 2004; 24: 495-501.

22. Pawlak K, Zolbach K, Borawski J, et al. Chronic viral hepatitis $\mathrm{C}$, oxidative stress and the coagulation/fibrinolysis system in haemodialysis patients. Thromb Res 2008, doi:10.1016/j.thromres.2008.02.012.

23. Pradhan AD, LaCroix AZ, Langer RD, et al. Tissue plasminogen activator antigen and d-dimer as markers for atherothrombotic risk among healthy postmenopausal women. Circulation 2004; 110: 292-300. 